\title{
National Cervical Cancer Coalition
}

National Cancer Institute

\section{Source}

National Cancer Institute. National Cervical Cancer Coalition. NCI Thesaurus. Code C39468.

The National Cervical Cancer Coalition (NCCC) is a non-profit organization focused on cervical cancer issues such as cervical cancer screening programs, new technology, research and treatment. The NCCC provides outreach support to cervical cancer patients and family members. 